\title{
DETECTION AND ANALYSIS OF METHANE EMISSIONS FROM A LANDFILL USING UNMANNED AERIAL DRONE SYSTEMS AND SEMICONDUCTOR SENSORS
}

\author{
Ignas Daugela ${ }^{1}$, Jurate Suziedelyte Visockiene ${ }^{1, \star}$ and Jurate Kumpiene ${ }^{2}$ \\ ${ }^{1}$ Department of Geodesy and Cadastre, Vilnius Gediminas Technical University, Vilnius 10223, Lithuania \\ ${ }^{2}$ Waste Science and Technology, Luleå University of Technology, 97187 Luleå, Sweden
}

Article Info:

Received:

26 November 2019

Revised:

11 February 2020

Accepted:

28 February 2020

Available online:

8 May 2020

Keywords:

Landfill

UADS

RGB

TIR

NIR

\begin{abstract}
Landfill operators must collect data on the topography of their landfills, their biological and hydrological characteristics, and local meteorological conditions. These data can be collected by satellite, using Unmanned Aerial Vehicles (UAVs), or by traditional methods such as static flux chambers or modelling. They serve as the basis for landfill monitoring, including the identification and measurement of methane $\left(\mathrm{CH}_{4}\right)$ gas emissions. Here, we present an approach for landfill mapping using sensor data from unmanned aerial drone systems (UADS) based on DJI Matrice 200 UAVs with Zenmuse X4S sensors and Trimble UX5 UAVs with Sony NEX-5R sensors. RGB (Red, Green, Blue) and near infrared (NIR) data from these sensors were processed using a Geographic Information System (GIS) to generate orthoimages, digital elevation models (DEMs), and normalized difference vegetation index (NDVI) maps. These were then used to evaluate changes in the surface structure and topography of the study area (Kariotiskes landfill, Lithuania). The NDVI maps were used to identify areas of sparse vegetation cover that may indicate localized $\mathrm{CH}_{4}$ emissions. Surface temperature maps based on thermal infrared (TIR) images were then prepared for analysis of these problematic areas. Finally, the presence of $\mathrm{CH}_{4}$ in these areas was investigated using a prototype lightweight gas sensor array. The structure of the Kariotiskes landfill site remained unchanged over three years, but there is evidence of possible $\mathrm{CH}_{4}$ gas influence at the landfill cover's surface. The combination of UADS-mounted imaging systems and the prototype gas sensor array enabled rapid analysis of emission hotspots and of landfill topography.
\end{abstract}

\section{INTRODUCTION}

European landfill operators are obliged to collect, treat, and use landfill gas (LFG) in landfills receiving biodegradable waste, and to monitor fugitive emissions. Modern European landfills have nearly impermeable top covers and LFG collection systems to reduce the amount of LFG escaping to the atmosphere. Nevertheless, localized uncontrolled LFG emissions occur frequently, which can contribute significantly to the global flux of greenhouse gases into the atmosphere. A top cover can effectively minimize $\mathrm{CH}_{4}$ emissions by promoting microbial $\mathrm{CH}_{4}$ oxidation (Stern et al., 2007, Thomasen et al., 2019; Fredenslund et al., 2019). Therefore, if spots with high $\mathrm{CH}_{4}$ emissions could be localized, it may be possible to take remedial action by stimulating $\mathrm{CH}_{4}$-oxidizing bacteria (Scheutz et al, 2017). Such localized high emission spots can account for as much as $50-75 \%$ of LFG emissions from modern landfills, but they are transient; their temporal and spatial distributions vary widely (e.g. Scheutz et al., 2003, 2008, Ishigaki et al., 2005, Spokas and Bogner, 2011, Xu et al., 2014, Lando et al., 2017). Effective monitoring systems are required to detect, quantify, and control such releases of LFG into the atmosphere.

Recent advances in the development of Remotely Piloted Aircraft Systems (RPAS) have expanded the applications of Unmanned Aerial Vehicles/Systems (UAV/UAS) in environmental research, enabling their use to detect potential $\mathrm{CH}_{4}$ release spots. Localized gas emissions from landfill sites can be identified and monitored by analyzing Remote Sensing (RS) data acquired using UAVs with mounted cameras and sensors (Abichou et al., 2006, USEPA, 2006, De la Cruz et al., 2016, Innocenti et al., 2017, Bourn et al., 2019, Fjelsted et al., 2019; Allen et al., 2019).

Digital ground models (DGM), also known as digital elevation models (DEMs), are prepared using RS data, which may be integrated into a GIS along with data on indicators 
of environmental conditions (Manzo et al., 2017). High resolution 3D surface models can then be prepared to detect and characterize events such as landslides, to evaluate the area affected, and to estimate the volumes and displacement rates of land masses (Tanteri et al., 2017, Daugela et al., 2018). This can enable rapid detection of surface deformations at landfill sites, which is important because cover stability is essential for preventing uncontrolled LFG emissions. Settlement and surface deformations may occur over time, disrupting the liner and forming cracks in the cover system, leading to the formation of localized $\mathrm{CH}_{4}$ release spots (e.g. El-Fadel and Khoury, 2000).

Because methane oxidation is exothermic, LFG escape spots exhibit elevated surface temperatures. Even if no oxidation occurs, temperatures inside a landfill can be substantially higher than in the surroundings, and LFG seeping through the cover will allow some of this heat to rise. Therefore, surface temperature measurement using thermal infrared (TIR) cameras can help reveal spots of uncontrolled LFG emission. Previous efforts to detect LFG escape spots at landfill sites using TIR imaging have yielded mixed results, primarily due to the limitations of current techniques (e.g. Desideri et al., 2007, Battaglini et al., 2013, Capodici et al., 2015, Fjelsted et al., 2019). It may therefore be necessary to combine TIR data with additional measurements to accurately monitor uncontrolled LFG emissions.

TIR cameras with infrared thermography imaging sensors can be used to detect temperature differences between released gases and the background atmosphere, and to identify those gases. Like many compounds, $\mathrm{CH}_{4}$ has absorption and emission bands in the infrared (IR) range, so imaging with multispectral IR cameras can enable identification of $\mathrm{CH}_{4}$ concentrations above $5 \%$ as well as detection of temperature differences of as little as 2.6 $\mathrm{K}$ (Kastek et al., 2009). Some authors have suggested that UAV platforms could be equipped with temperature/humidity sensors together with an on-board high-precision near-infrared (NIR) $\mathrm{CO}_{2}$ sensor (Allen et al., 2019) to increase the reliability of LFG detection. NIR sensors, which rely on photonic crystals that create an optical absorption path, were initially used to identify and measure gases in laboratory settings (Kamieniak et al., 2015). The technology has been further developed for field use, enabling NIR cameras to be mounted on UAVs and used for aerial imaging of e.g. vegetation.

Vegetation on a landfill's top cover may affect and be affected by LFG emissions, and irregularities in vegetation cover could indicate the presence of problematic spots. Plant roots can form channels and macropores in soil that facilitate $\mathrm{O}_{2}$ diffusion and $\mathrm{CH}_{4}$ supply to bacteria, stimulating $\mathrm{CH}_{4}$ oxidation (Abichou et al., 2015, Ndanga et al., 2015). If the soil moisture content is sufficiently high, plant roots may also provide a favorable environment for $\mathrm{CH}_{4}$-oxidizing bacteria (Feng et al., 2017), which play a key role in reducing $\mathrm{CH}_{4}$ emissions from landfills. LFG in the root zone can cause $\mathrm{O}_{2}$ deficiency and asphyxia in plants. Although $\mathrm{CH}_{4}$ in the root zone has no major effect on plants (Arif and Verstraete, 1995), $\mathrm{CO}_{2}$ concentrations above $20 \%$ are phytotoxic even if sufficient $\mathrm{O}_{2}$ is present (Gendebien et al., 1992). Some species are more tolerant than others and are affected by escaping LFG differently, so plant density and species richness can be utilized as indicators of LFG emissions (Maurice et al., 1995). But time-efficient observations are only possible by digital imaging. The biophysical and physiological characteristics of vegetation using digital imagery has been modelled since the technology became available (Zhang et al., 2009, Thenkabail, 2015). Many of these studies involve the use of vegetation indices and the application of complex mathematical equations to image bands to measure the relative greenness of image features. A notable graphical indicator of plant greenness is the normalized difference vegetation index (NDVI) (Bhandari and Kumar 2012, Gandhi et al., 2015). NDVI is widely used in RS to detect and quantify healthy vegetation cover and has been tested in landfill monitoring (Yang et al., 2008; Mohamood et al., 2016).

Multiple techniques are available for $\mathrm{CH}_{4}$ monitoring and their combinations have been applied to improve location and quantification of $\mathrm{CH}_{4}$ landfill emissions (Fjelsted et al., 2019; Mønster et al., 2019). Combined analysis of changes in landfill surface topography, temperature, and vegetation cover could enable fast and reliable hotspot detection if complemented with quantitative $\mathrm{CH}_{4}$ measurements. However, the size and weight of high precision $\mathrm{CH}_{4}$ measuring instruments preclude their use on UAVs. Direct measurements of LFG emissions at the landfill surface are challenging due to their spatial and temporal variability and also because of the technical limitations and commercial unavailability of existing measurement techniques (Mønster et al., 2019; Hildmann and Kovacs, 2019). The large areas and complex topography of landfills further complicates the application of traditional direct measurement methods such as flux chambers (e.g. Scheutz et al., 2003, 2008, 2011, Gebert and Gröngröft, 2006) or walkover surveys with portable analyzers (Lando et al., 2017). It would therefore be desirable to adapt small and inexpensive sensors developed for other applications (e.g. gas leak detectors) for use at landfills. The main barrier to using such sensors to quantify LFG emissions is interference due to atmospheric conditions. Since changes in landfill surface topography, temperature, or vegetation cover are frequently but not necessarily associated with LFG emissions, it would be sensible to only use $\mathrm{CH}_{4}$ sensors to validate the identified potential hotspots by confirming the occurrence of $\mathrm{CH}_{4}$ emissions.

The aim of this study was to develop a costeffective landfillsite analysis method that could integrate various benefits of an unmanned aerial drone system (UADS) 1) to remotely localize $\mathrm{CH}_{4}$ emission spots at a closed landfill site by evaluating changes in surface structure and topography, thermal maps, and vegetation cover indices based on RGB, NIR, and TIR imaging data; and 2) to detect the presence of $\mathrm{CH}_{4}$ and $\mathrm{CO}_{2}$ in those spots using gas sensors that may be suitable for future mounting on UADS.

\section{MATERIALS AND METHODS}

\subsection{Study area}

The study object was Kariotiskes landfill, located in Trakai district, $25 \mathrm{~km}$ from Lithuania's capital city, Vilnius 
at $54.716111^{\circ}, 24.959167^{\circ}$ in WGS84 coordinate system. This landfill has been used for unsorted municipal solid waste disposal since 1987.

About $3 \mathrm{mln}$. $\mathrm{m}^{3}$ of waste was landfilled over 20 years in a 27.6 ha area. A 0.5 m thick clay layer and a high-density polyethylene geomembrane comprise the landfill bottom liner. The landfill has a leachate collection system that transfers the leachate to a wastewater treatment plant for treatment. Groundwater monitoring wells are installed around the landfill: four in the direction of groundwater flow and one against the flow.

The Kariotiskes landfill was closed in 2008 in accordance with EU regulations on landfill closure. A cover consisting of a drainage layer, a protective liner and a vegetation layer was placed above the landfill. Gas extraction wells and a gas collection system were installed in 2010, and a power plant was built to convert the LFG into electricity. During the gas extraction, testing the composition of the collected gas samples was performed by C.A.U. analytical laboratory (Germany). The proportions of the major components were as follows: $57 \% \mathrm{CH}_{4}, 30 \% \mathrm{CO}_{2}, 12 \% \mathrm{~N}_{2}$ $1 \%$ other gases.

A RS methodology was used for object analyses and to extract information from the acquired (RGB, NIR, TIR) imaging data. These processes involve many different algorithms and can be used to acquire meaningful information from images (Prasad et al. 2015; Yuan et al., 2019), which may be acquired using a satellite system or a UADS platform equipped with various sensors.

\subsection{The UADS platform and data}

The Kariotiskes landfill imaging done with two types of UADS: a commercial UAV DJI Matrice 200 quadrocopter and Trimble UX5 Aerial Imaging Rover. DJI Matrice 200 quadrocopter with Zenmuse X4S sensors (spectral configurations RGB and TIR) was used for imaging in 2018. This UAV weighs $4.53 \mathrm{~kg}$, with unfolded dimensions of $887 \times 880 \times 378 \mathrm{~mm}$. Its maximum payload is $6.14 \mathrm{~kg}$. For navigation and control, the UAV was equipped with a Global Positioning System (GPS) receiver, a basic inertial system, and distance sensors. Its hovering accuracy in special
P-mode with good GPS reception and the Downward Vision System (DVS) enabled was $\pm 0.1-0.5$ m vertically and \pm 0.3 $\mathrm{m}-1.5 \mathrm{~m}$ horizontally. The Zenmuse X4S camera used in the DJI Matrice 200 weight is only $253 \mathrm{~g}$, it could be flight under 35 minutes (RGB imaging) and 28 minutes (TIR imaging) and have the Controllable Range.

Trimble UX5 UAV equipped with a Sony mirrorless NEX$5 R$ digital camera (spectral configurations RGB and NIR). At a flying height of $150 \mathrm{~m}$, the Trimble UX5 achieves a Ground Sampling Distance (GSD) of $4.8 \mathrm{~cm}$. It can also achieve a GSD of $2.4 \mathrm{~cm}$ when flying at altitudes as low as $75 \mathrm{~m}$ above ground level (AGL). Operation at such low altitudes requires faster shutter speeds on the camera to prevent forward motion blur. The Sony NEX-5R camera used in the Trimble UX5 is capable of using the higher ISO values necessary to compensate for the darkness resulting from such high shutter speeds while maintaining acceptable levels of noise for photogrammetric applications (Cosyn and Miller, 2013). The Trimble Access Aerial Imaging application can be used for mission planning in the office or at a Ground Control Station (GCS). The user defines the project area and avoidance zones by drawing them over an industry-standard map interface and also specifies the flight height AGL, GSD, and desired image overlap. Trimble Access then calculates the number of flights, flight pattern, and duration of flight(s) needed to meet the user's specifications. After locations for take-off and landing have been selected, the UADS is taken to the field to perform the flights (Cosyn and Miller, 2013).

Figure 1 summarizes the types of raw data acquired in this study, the products (3D models, maps, and images) generated from UAV data, and the uses of these products.

Table 1 presents information on the flights that were undertaken during this work, the number of images captured, and the spatial resolution of the images for three sensor types. The spatial resolution is defined based on the number of pixels used to construct the images. All images were acquired during spring (usually around May) in 2015,2016 , or 2018.

High spatial resolution (Table 1) RGB images were obtained using DJI Matrice 200 and Trimble UX5 UAVs in the

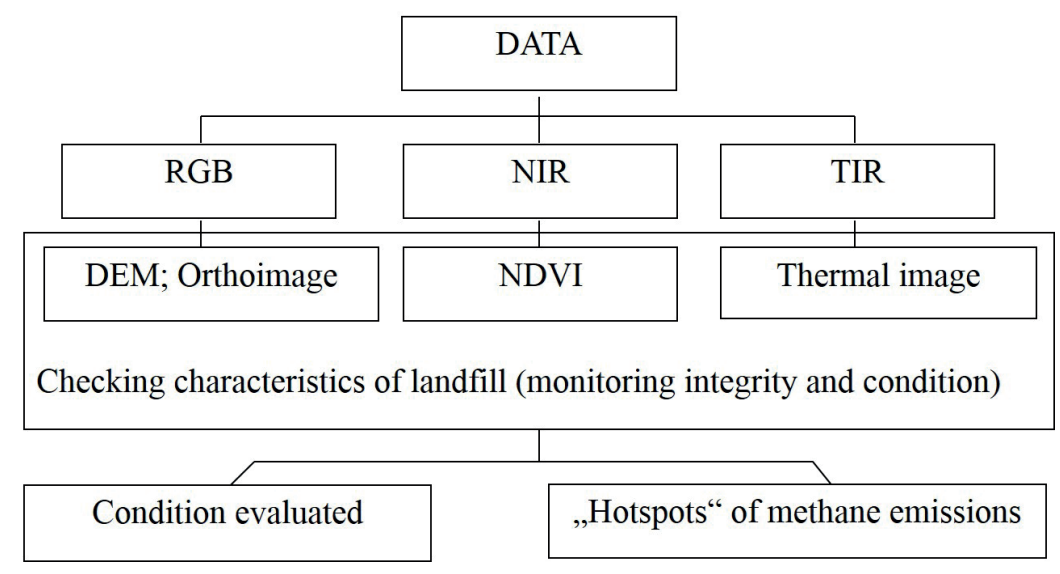

FIGURE 1: Data types used in this study; the images, maps, and models generated by processing the acquired data; and the use of these images, maps, and models to analyze methane emissions. 
TABLE 1: Flight characteristics.

\begin{tabular}{|c|c|c|c|c|c|c|}
\hline Sensor & $\begin{array}{l}\text { Spatial resolution } \\
\text { (m) }\end{array}$ & $\begin{array}{l}\text { Number of } \\
\text { images }\end{array}$ & $\begin{array}{c}\text { Flight } \\
\text { height }(m)\end{array}$ & $\begin{array}{l}\text { Flight } \\
\text { time (min) }\end{array}$ & $\begin{array}{l}\text { Image series } \\
\text { time (year) }\end{array}$ & $\begin{array}{l}\text { Processing } \\
\text { software }\end{array}$ \\
\hline \multirow[t]{3}{*}{ RGB } & 0.14 & 40 & 470 & 5 & 2015 & $\mathrm{TBC}$ * \\
\hline & 0.04 & 419 & 140 & 21 & 2016 & TBC \\
\hline & 0.13 & 333 & 70 & 10 & 2018 & UAS Master \\
\hline TIR & various & 22 & various & - & 2018 & - \\
\hline NIR & 0.02 & 686 & 77 & 22 & 2018 & TBC \\
\hline
\end{tabular}

*TBC - the Trimble Business Center Software Photogrammetry Module

years 2015, 2016 and 2018. Flights were performed at a range of altitudes, resulting in the acquisition of 40 images in 2015, 419 images in 2016, and 333 images in 2018. The RGB data acquired in 2015 and 2016 are equivalent to the ground spatial distance (GSD) values for the orthoimages and colorized surface models generated by processing this RGB data. The quality of an image depends on the subject's characteristics, camera optics (sensor resolution), and atmospheric conditions at the moment of shooting. The photographic images were processed using photogrammetric methods (Förstner and Wrobel, 2016) involving (i) determination of inner orientation; (ii) determination of relative orientation (triangulation); (iii) photogrammetric (3D) model creation; and (iv) integration of ground control points and absolute orientation (projective transformation) to generate a new 3D point cloud (DEM) or orthoimage.

Vegetation and cover observations results were generated using Trimble UX5 UAV data acquired in 2018. The NIR sensor (a Sony mirrorless NEX-5R camera) was used to capture two colored bands and one NIR band. The spatial resolution of the NIR images was $0.02 \mathrm{~m}$, i.e. each pixel corresponded to an area of $1.9 \times 1.9 \mathrm{~cm}$ on the ground. Vegetation cover levels were assessed by computing per-pixel NDVI values based on the NIR data. NDVI values can range from +1.0 to -1.0 . Low values ( 0.1 or less) correspond to areas of barren rock, sand, or snow; moderate values ( 0.2 to 0.5$)$ correspond to sparse vegetation such as shrubs, grasslands, or senescing crops; and high values ( 0.6 to 0.9 ) correspond to dense vegetation (temperate and tropical forests or fully grown crops) (Remote Sensing Phenology, 2018; NASA, 2018). NIR imaging data were used to create thematic NDVI maps via the work steps (algorithm) outlined in Table 1 of supplementary material.

The NDVI values were calculated and assigned to orthoimage pixels based on absolute position using the local coordinate system (LKS94). The NDVI is computed using the Eq. (1) below (Xie et. al. 2008, NASA, 2018, Remote, 2018):

$$
N D V I=(N I R-R E D) /(N I R+R E D)
$$

where NIR and RED denote the intensity of the near infrared and red bands, respectively.

Orthoimages and point clouds were generated using the TBC software and colored using NirGB (eCognition software).

TIR images were collected with a UADS DJI Matrice 200 with Zenmuse XT sensor $(8-9.2 \mu \mathrm{m})$. The sensor's output was processed using an on-board computer and immedi- ately converted into radiant temperatures, so the resulting image information consisted of a single band. Before use, the sensor was calibrated in a laboratory environment and a sensor certificate was obtained. The processed images show the minimum and maximum temperature of each frame pixel; the pixels with the highest temperature within a frame were identified in real time. The images were also tagged with the UAV's GPS position and heading at the time of acquisition for geo-referencing. Finally, to generate a visual representation of the imaging data, ortho-rectification was performed and a color-thematic map was applied based on the pixel values. The color mapping was chosen to highlight the features most relevant to the analysis (i.e. the spatial variation of stream temperatures) and the interpretation of problematic areas.

\subsection{Concentration screenings by walk-overs}

Areas identified as potential $\mathrm{CH}_{4}$ release hotspots were investigated using a newly constructed prototype device with semiconductor-based sensors to measure changes in $\mathrm{CH}_{4}$ levels and detect unusually high (>21\%) levels of $\mathrm{CO}_{2}$ relative to background gases. The prototype was created from inexpensive parts that are readily available via web portals such as www.adafruit.com or www.aliexpress. com. These parts include a 2-line LCD display unit with an I2C interface for showing real-time values, a Real Time Clock (RTC) module with a micro SD card reader for storing readings with current time and relative session time stamp, and a Bluetooth module for sending real-time data to a mobile device (e.g. a mobile phone or laptop). Readings and communications are processed by an Arduino Uno microcontroller fitted with a DHT22 temperature and specific humidity sensor capable of measuring humidities between 0 and 100\% (accuracy: 2-5\%) and temperatures between -40 and $80^{\circ} \mathrm{C}$ (accuracy: $\pm 0.5^{\circ} \mathrm{C}$ ) at a maximum sampling rate of $0.5 \mathrm{~Hz}$ (once every 2 seconds). The gas sensing array comprises 3 Arduino modules (MQ2, MQ4, and MQ135). Each sensors (models) have different sensitivity in terms of readings (values). It can be altered by changing circuit. Each sensor can be damaged while exposed to extreme conditions over prolonged time. Other than that, it is easily exchanged and can be recalibrated quickly as well as upgraded to newer version or model with better characteristics (even factory pre-calibrated). This study is based on testing methods, so before going into field it was verified in laboratory. The MQ2 module is sensitive to $\mathrm{CH}_{4}, \mathrm{C}_{3} \mathrm{H}_{8}$, and $\mathrm{C}_{4} \mathrm{H}_{10}$; MQ4 is sensitive to $\mathrm{CH}_{4}$; and MQ135 is sensitive to $\mathrm{CO}_{2}, \mathrm{C}_{6} \mathrm{H}_{6}, \mathrm{NH}_{3}$, and $\mathrm{NO}_{x}$. These sensors are mainly used 
as "air quality" sensors in various industrial and household appliances and are sensitive to deviations from the composition of the common unpolluted air mixture. Each sensor's output was recorded on a micro SD card once per second as plain text, enabling import into tables or databases for further processing. The sensor data were also used to generate plots of measurements over time and scatter plots. The most important sensor in this work was the MQ4 module because its $\mathrm{SnO}_{2}$ sensing layer is designed to specifically detect $\mathrm{CH}_{4}$ while suppressing noise due to alcohol, flame fumes, and cigarette smoke. The more $\mathrm{CH}_{4}$ in the air flow around this module, the higher its output voltage (which is capped at $5000 \mathrm{mV}$ by the microcontroller's specifications). The device was coupled to a Spectra Precision SP60 Global Navigation Satellite System (GNSS) receiver to accurately record its location.

The prototype gas sensing device calibration was done in laboratory environment. For tests, a sealed non-diffusing gas collection bag was used. Air from the bag was evacuated using an air compressor before the test. After the electronic parts warmed up (constant readings achieved) a controlled amount of gases was injected through a system of valves using a glass syringe. Calibration gases were obtained from AGA Gas AB. A table of five points with increasing known amounts of $\mathrm{CH}_{4}$ and other gases was made. Each concentration was compared to electronic value obtained by averaging several $300 \mathrm{sec}$ readings. Three similar tests were conducted with different concentrations of $\mathrm{CH}_{4}$ and background gases. The results for $\mathrm{CH}_{4}$ are presented in the Figure 1 of supplementary material, regression equation was derived and with $r$ squared of 0.9998 calculated for MQ4 sensor.

Field measurements were conducted by holding the device $25 \mathrm{~cm}$ above the ground surface (Figure 2), i.e. the gas-sensing array was not mounted on the drone when measuring in the study landfill (although such possibility was tested elsewhere). The maps were used to measure gas concentrations in localized areas. The prototype device was calibrated against $\mathrm{CH}_{4}$ and $\mathrm{CO}_{2}$ in the laboratory to verify that its sensors respond proportionally to these gases.

The microcontroller calculates changes in the relative abundance of the gases its sensors detect in real-time in the field. The raw sensor data are recorded together with real-time clock and geographic position data, facilitating data processing and cleaning.

\section{RESULTS AND DISCUSSION}

The first part of this section described the result changes of landfill surface structure and topography. After that, it is presented vegetation and termal imaging and result of methane and carbon dioxide measurement.

\subsection{Landfill surface structure and topography}

While the details of the orthoimages differ, the vegetation cover at the site clearly improved over time, becoming greener and denser. Figure 3 (a) and (b) show 3D surface models based on RGB data acquired in 2015 and 2016, which have very similar appearances. In particular, there are no appreciable differences in the size or distribution of vegetation-covered spots. All flights were performed on moderately sunny days with low wind speeds and no precipitation. A more powerful UAV and more sophisticated software were used in 2018, enabling better feature matching, structure from motion photogrammetry, and classic aerial triangulation blunder detection. Triangulation was performed based on the 10823 automatically collected tie-points in the 333 RGB sensor images. The data were processed in $10 \mathrm{~min} 41 \mathrm{~s}$, and a natural-colored point cloud was generated, yielding the $0.14 \mathrm{~m}$ GSD orthoimage shown in Figure 3 (c) (Daugela et. al., 2018). The point cloud was also used to generate the DEM shown in Figure 3 (d), which is colored by elevation; the colors repeat at elevation intervals of $10 \mathrm{~m}$, starting from blue. The highest point in the site
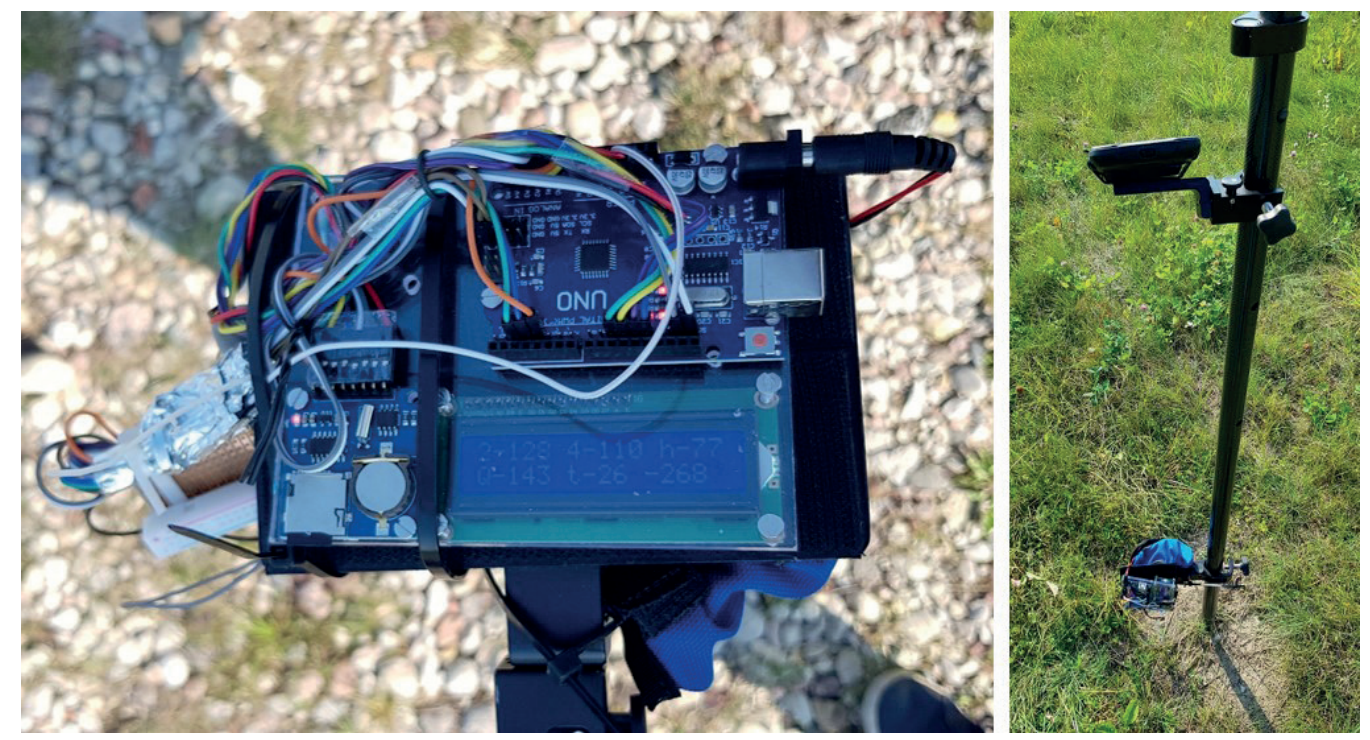

FIGURE 2: Close-up of the prototype gas sensing device (left) and the device affixed to a pole, $25 \mathrm{~cm}$ above ground level, to perform a gas measurement (right). 

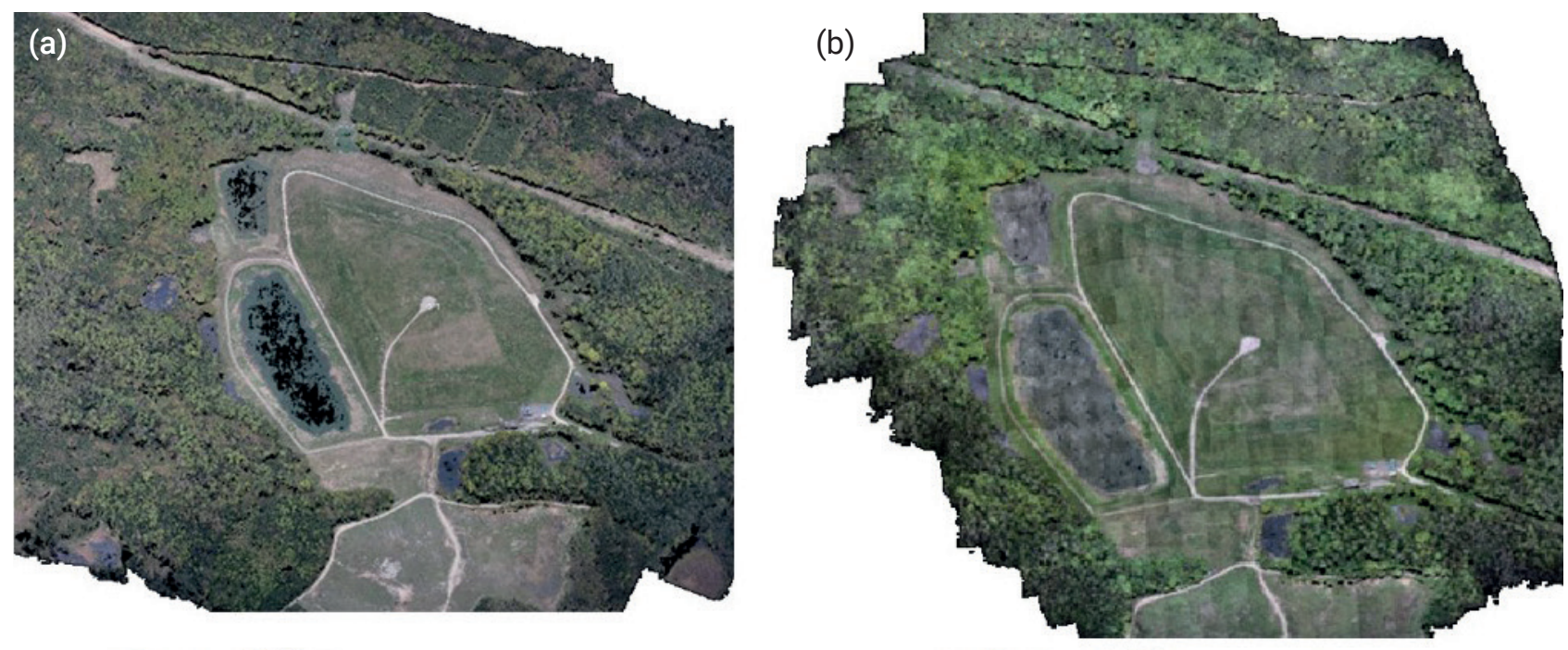

(c)

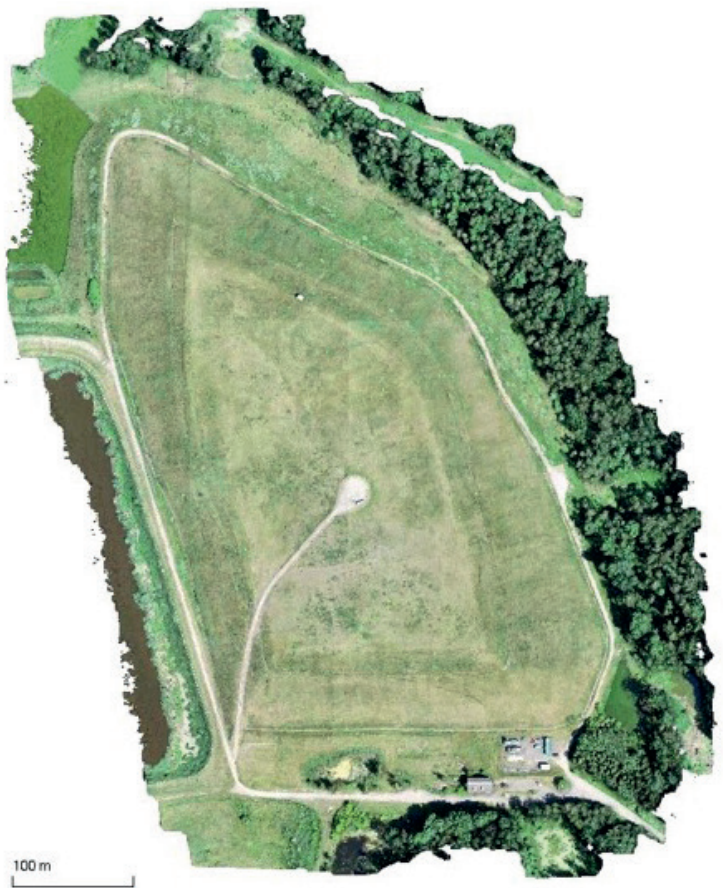

(d)

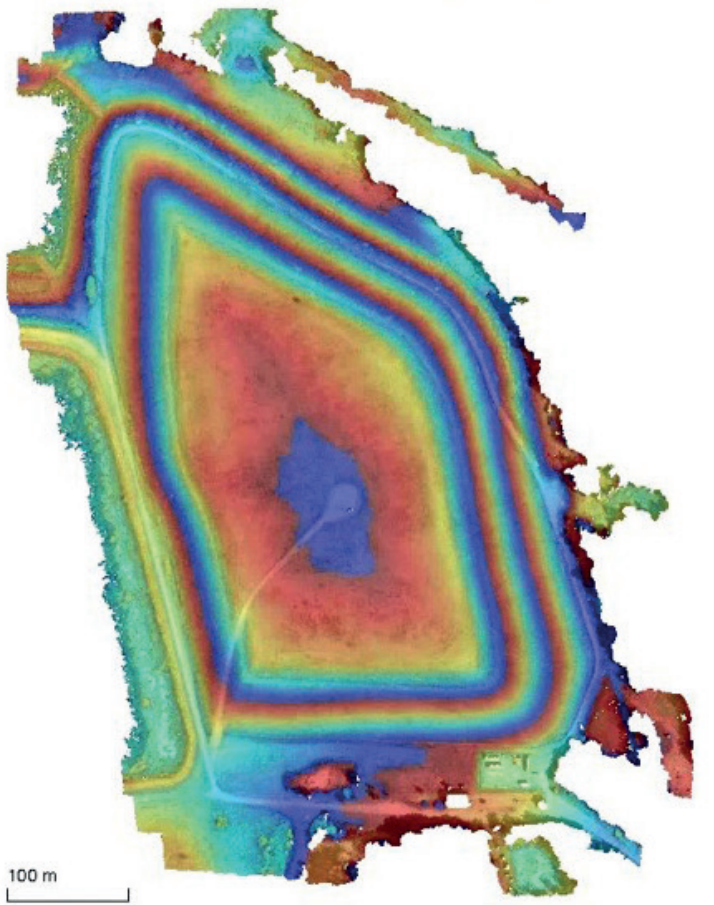

FIGURE 3: 3D surface models of Kariotiskes landfill in a) 2015; b) 2016; c) 2018 and d) Digital elevation model based on the 2018 3D model.

(altitude: $161.8 \mathrm{~m}$ ) is the small blue area in the center of the image; its altitude was used as the origin height. To identify changes in the site's visible surface level and structure over time, transparent orthoimages based on data acquired in 2015, 2016, and 2018 were superimposed on one-another (see Figure 4).

The coloration of the orthoimages makes it difficult to identify small changes in color (and thus small changes in surface height or structure). Therefore, to better detect changes in relief, automated change detection based on distances between digital surfaces was performed using the Trimble RealWorks program.

RGB information was compared by interpolating Z (height) values between the years 2015 and 2018, yielding the results shown in Figure 4 (b). Surfaces were matched with an average error of $39 \mathrm{~mm}$ between points in most cases, so the measurement error was minimal. The deviation in the $Z$ distance (height) between 2018 and 2015 was within $2 \mathrm{~cm}$ for most points, with no areas showing markedly larger deviations (see Figure 4 (c)). The processed RGB images for the period 2015-2018 showed that the landfill's surface structure and topography had not changed. This suggests that the protective top cover's integrity has not been reduced by processes such as settling and that the cover should therefore still be functioning well.

Remedial efforts to mitigate localized fugitive $\mathrm{CH}_{4}$ emissions ideally require fast, cost-efficient, and user-friendly methods for hotspot localization. RGB photo-images, such as those taken in this study, are easily converted into orthoimages and DEM results, which can then be used to detect 

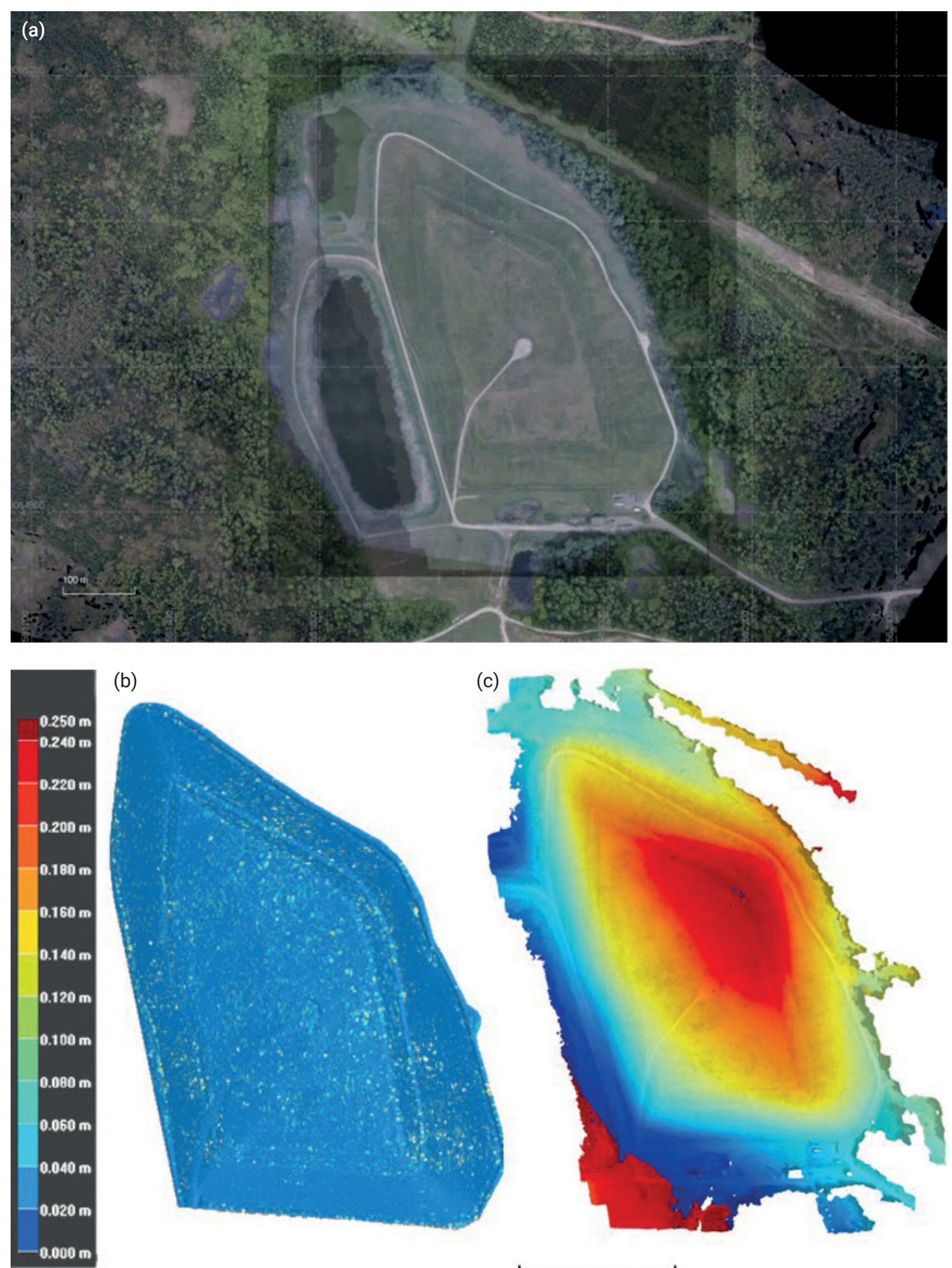

(b)

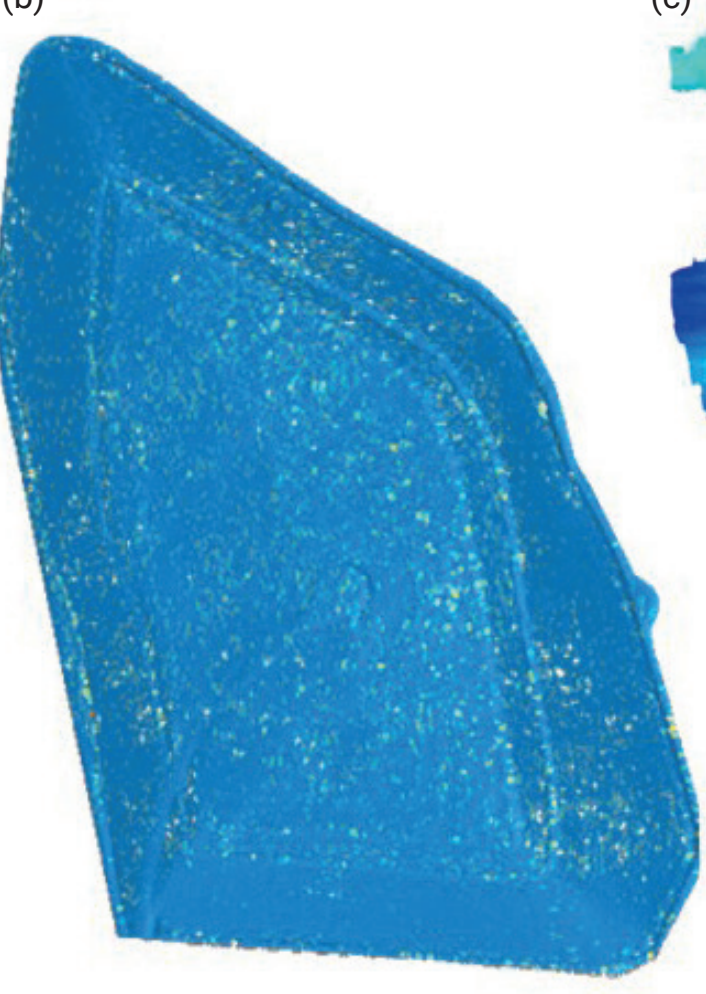

(c)

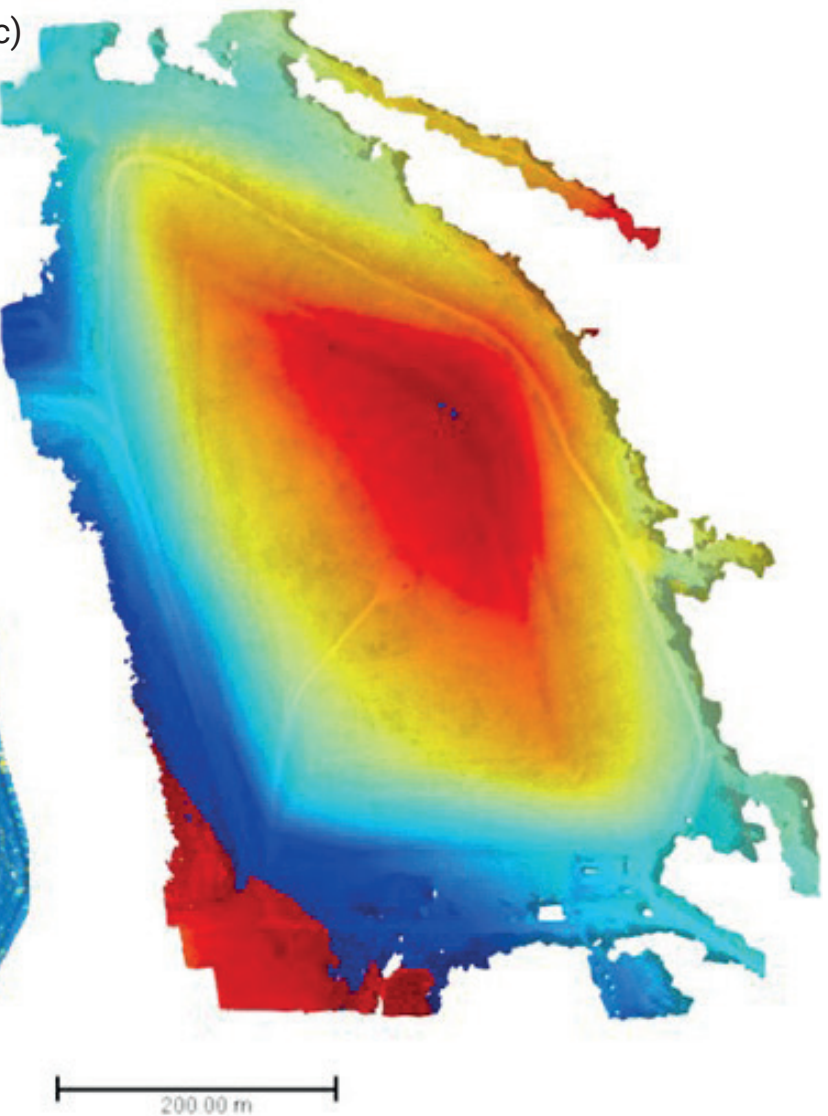

FIGURE 4: Results: a) layered RGB orthoimage based on data acquired in 2015, 2016, and 2018; b) change in elevation between 2015 and 2018; c) elevation model based on RGB data from 2018. 
changes in landfill topography annually or on demand. It took only 5-21 minutes to collect imaging data covering the entire area of the landfill site (which extends over about 30 ha). RGB data recommended around $5 \mathrm{~cm}$ GSD, as well as NIR ( $2 \mathrm{~cm}$ GSD was too dense, too heavy for effective calculations). No detectable changes in topography and surface structure were identified at the site over the three-year study period. This indicates that the landfill, which was covered about ten years before the study began, was mechanically stable and that no settlement or surface deformation that could damage the cover structure occurred during the study period.

\subsection{Vegetation and Termal imaging}

Figure 5 (a) shows an NIR-based orthoimage of the landfill in which identifiable protruding pipes belonging to the LFG recovery system's wells are indicated by triangles.

A 3D surface model based on the NIR point cloud is shown in Figure 5 (b), and an NDVI map of the studied area based on the NIR data is shown in Figure 5 (c). Areas with NDVI values of 0.1-0.2 (shown in red) may contain vegetation experiencing water stress due to LFG exposure. Automated Object Based Image Analysis (OBIA) was used to create a thematic map in which these problematic areas are highlighted in red (Figure 5 (c)). In this process, each pixel's NDVI value was calculated based on its red and NIR intensities. These values were then used to generate cells, which were grouped to represent distinct objects, each of which was then analyzed. Objects with NDVI values below 0.2 were identified as potentially problematic areas and colored in red. They were then exported as polygons in shape files (geodatabase), while the thematic layers were combined to create an oriented geoTIFF image.

Analysis of NIR imaging data revealed several spots on the landfill surface that had low NDVI values (i.e. areas with little greenness or dried up vegetation). Moreover, (a)

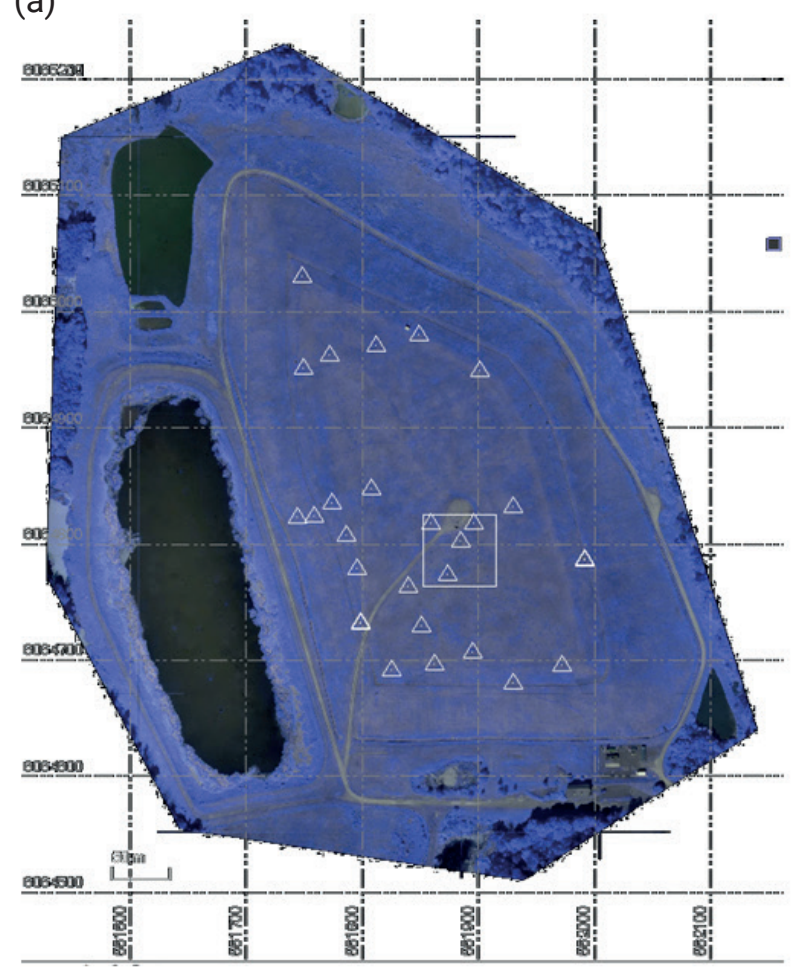

(c)

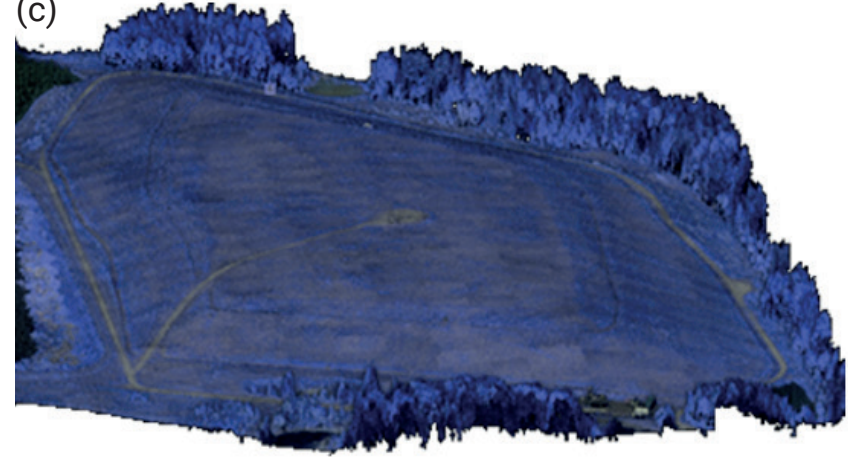

(b)
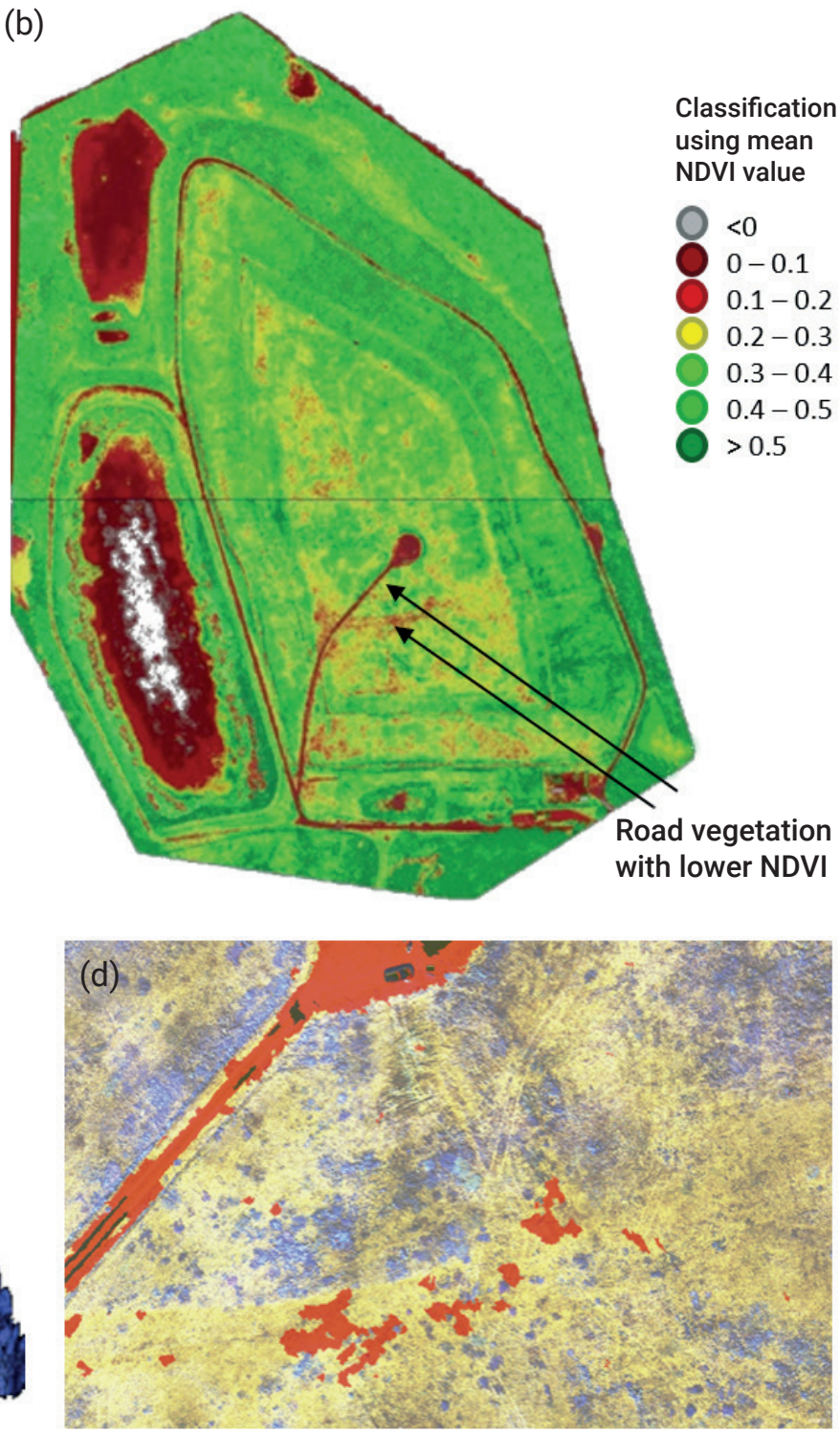

FIGURE 5: NIR imaging of the landfill surface: a) NIR orthoimage with triangles indicating identifiable LFG recovery pipes; b) 3D surface model derived from NIR point cloud; c) NDVI map; d) Thematic map with problematic areas of low NDVI highlighted in red. 
TIR imaging revealed that many of these areas also had slightly elevated surface temperatures. The co-occurrence of these findings (which individually are not necessarily sufficient to identify potential areas of concern) enabled fast (22 min flight time plus data processing) and relatively easy identification of potentially problematic areas. Thermal images could also be combined to cover all area in one orthophotograph and done only when surface is cold (for anomalies to stand out).

Stronger voltage signals were observed upon testing with a prototype microcontroller-based gas sensor array at some spots, indicating elevated methane concentrations relative to the surroundings.

TIR images were generated from data acquired using the DJI Matrice 200 UAV in 2018. Images were acquired in areas found to have unusually low NDVI values to determine whether their temperatures differed from those of their surroundings (Figure 6, purple colour). The cells of the grayscale images were colored according to their measured temperatures and the temperature data were prepared for analysis to identify correlations.

\subsection{Methane and carbon dioxide measurement}

The prototype device containing the semiconductor sensors was used to determine the levels of $\mathrm{CH}_{4}$ and $\mathrm{CO}_{2}$ in the air above the previously identified problematic areas of the landfill. The readings of each gas sensor in millivolts are presented in Figure 7, which shows uncorrected and uncalibrated values measured when walking around the Kariotiskes landfill site (see the Figure 2 in the Supplementary Material).

Measurements acquired with the MQ2 and MQ135 sensor modules are shown in blue and green, respectively (Figure 7). The green line can be interpreted as a measure of air pollution; a high voltage from the MQ135 sensor typically indicates comparatively high $\mathrm{CO}_{2}$ levels and low $\mathrm{O}_{2}$ levels. The MQ2 sensor (blue) responds to $\mathrm{CH}_{4}$ and $\mathrm{CO}_{2}$ with similar strength and is sensitive to all explosive gases. MQ4 sensor's high voltages from 500 to $760 \mathrm{mV}$ (and thus possible higher gas levels) were observed during the first 200 or so seconds of the sampling period because the device was initially placed in the vicinity of a gas collection well. The sudden decrease in voltage at the end of this period could be due to an increase in wind speed and/ or changes in temperature and humidity. The increase in voltage from 530 to $610 \mathrm{mV}$ between 950 and $1400 \mathrm{sec}-$ onds occurred when the device was moved to the site's northern slope, in locations found to have much less vegetation cover than the rest of the site based on NDVI analysis. The middle section of the graph shows measurements made at various places at the top of the hill (in the central area of the site). The section from roughly 3500 seconds onwards shows measurements made at various place in the southern part of the Kariotiskes landfill. The low readings from 390 to $440 \mathrm{mV}$ in this region are likely due to dispersal of the measured gases by wind. In addition, these measurements were conducted at around midday, when the temperature was around $8^{\circ} \mathrm{C}$ higher and the specific humidity around $26 \%$ lower than they were when the first measurements were conducted. Device as it is described should be used for qualitative detection, not aiming to detect exact quantities, but speeding process of finding spots where precise measurements of quantity is needed. To get most out of such sensors: temperature should be chosen similar to the calibration and factory recommended (in our case around $22^{\circ} \mathrm{C}$ ); wind should not be strong or housing with constant internal flow made; strong gradient in humidity should be avoided, if changes not compensated by real time or post-processing algorithm.

If these sensors found to be not suitable for some particular measurements in landfill sites, then they can be changed into newer or with better characteristics easily, in most cases without much altering the code or circuit and some might be found factory pre-calibrated.

While the prototype device is not yet capable of quantitative gas concentration measurement, the results clearly show that combining drone-based infrared imaging with simple gas detection sensors could give landfill operators useful and cost-efficient tools for rapidly identifying local-
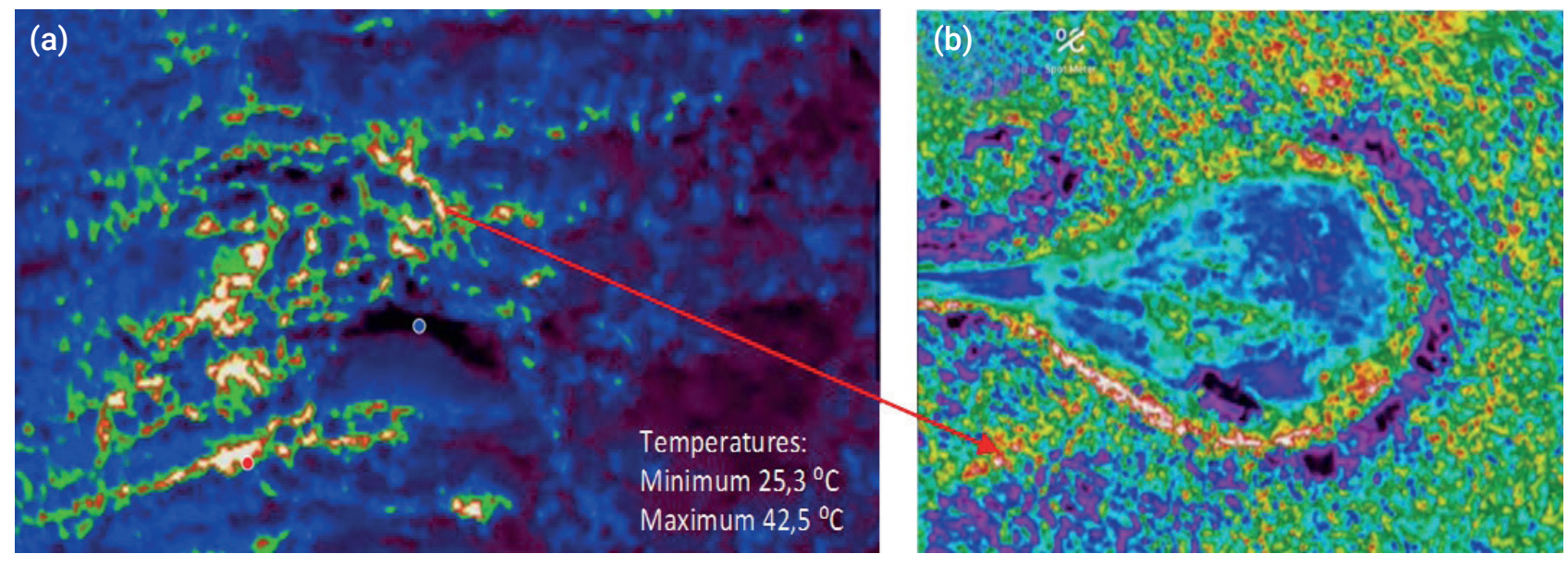

FIGURE 6: Thermal images from the TIR sensor. Pixels are colored according to their temperature values; the color scale goes from red (high temperature) to violet (low temperature). a) a point of interest imaged from an altitude of $31 \mathrm{~m}$; b) a larger area imaged from an altitude of $122 \mathrm{~m}$. 


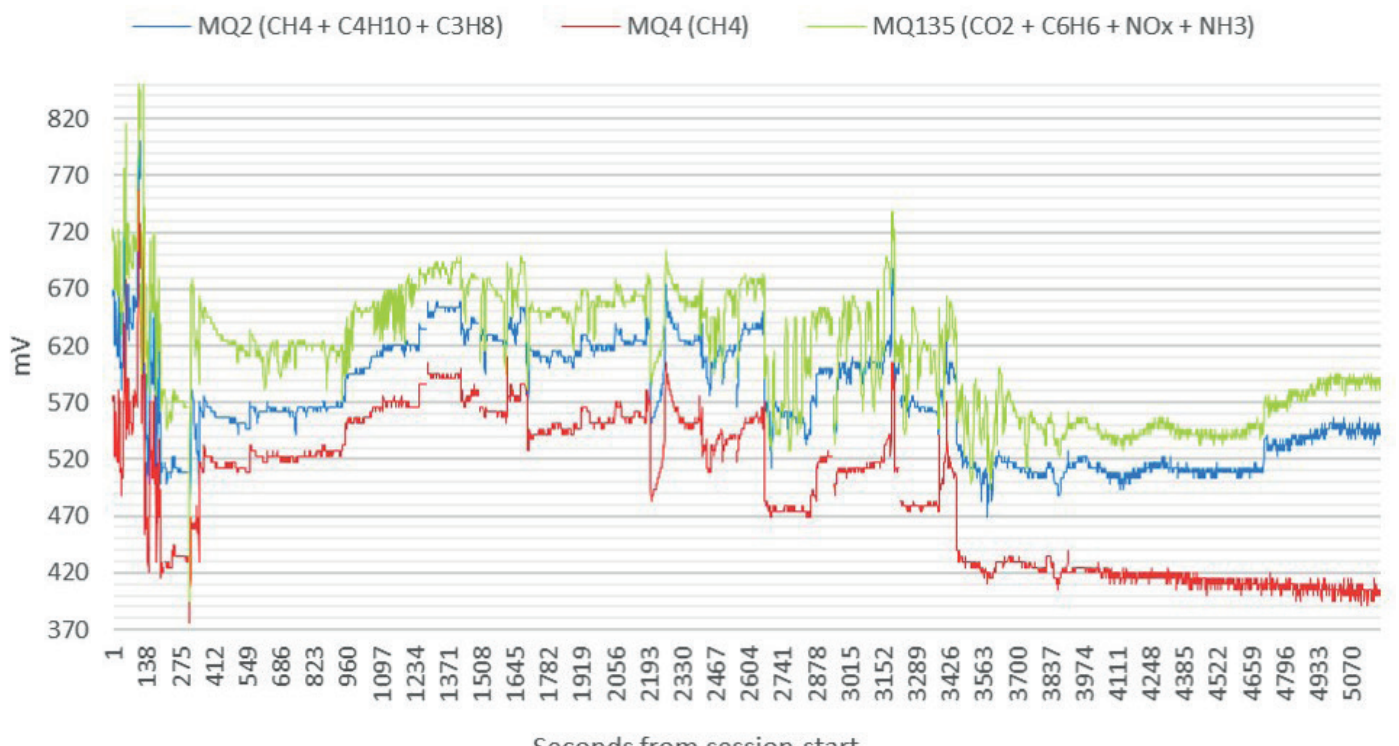

FIGURE 7: Voltage signals generated by the semiconducting $\mathrm{CO}_{2}$ and $\mathrm{CH}_{4}$ sensors above the identified problematic areas of the landfill surface as functions of time.

ized $\mathrm{CH}_{4}$ emissions. The power of techniques used is likely to increase in future as software and UAVs become more capable: the use of an improved UAV and more sophisticated desktop software in 2018 allowed better results to be achieved in less time than was required in 2015 and 2016. Additionally, the cost of the equipment and software necessary for imaging could be reduced up to 2.5 -fold in cases where RGB data with a mediocre spatial resolution would be adequate. This method (with low cost gas sensor) has shortage of exactly identifying gas type, as mostly it reacts to several gases and is only more sensitive to one of them. Although it can be calibrated more accurately to one specific gas, it must be used in known environment in order to rely on results. In case of landfill sites, any kind of gases detected by these sensors are unwanted. False positive is possible because of meteorological conditions and construction of form factor. False negatives have almost zero chance when performing qualitative detection, while a bigger chance of false negatives is possible in quantitative detection if instrument is calibrated incorrectly or used in strongly different environmental conditions than those at calibration.

Further, to improve results, measurements of temperature and humidity with fixed amount of $\mathrm{CH}_{4}$ will be conducted in the future and calibration for these two parameters are planned, which will be taken into account by the real time $\mathrm{CH}_{4}$ measurement algorithm.

Another factor influencing reading values is power source. It must be redesigned, to be stable at least to 0.1 $\mathrm{mV}$ and separated from electronical sensing parts. This way it will not be a source of error for calibration and field measurements or influence precision of repeated field measurements. All parts must be tested by experienced electrician and if found according to specification and sufficient for device, then not changed or altered, otherwise the whole device needs to be recalibrated in laboratory. Sensor fusion techniques can be applied while more exper- iments conducted with this prototype, as well as machine learning algorithms could improve or change common calibration routine.

\section{CONCLUSIONS}

The use of a prototype microcontroller-based gas sensor array, that is suitable for future mounting on UADS, together with imaging systems mounted on unmanned aerial drones enabled remote localization of potential $\mathrm{CH}_{4}$ emission hotspots at the closed Kariotiskes landfill site. Although the site's surface structure and topography remained unchanged over the three-year study period, analysis of surface temperatures and vegetation cover based on RGB, NIR, and TIR imaging data revealed several spots of interest. Testing with the gas sensor array confirmed the possible presence of elevated $\mathrm{CH}_{4}$ concentrations in these spots. The combination of thermal and vegetation imaging using infrared cameras with commercially available gas sensors thus offers a relatively simple and inexpensive way to rapidly identify $\mathrm{CH}_{4}$ release hotspots in closed landfill sites. Although the developed gas-sensing array was used in this study as a handheld instrument, it has a full potential to be mounted on the drone for remote measurements. This approach should be affordable for landfill operators and, with further development, could be used to quantify fugitive $\mathrm{CH}_{4}$ emissions over an entire landfill surface.

\section{AKNOWLED GEMENTS}

The authors thank the employees of the Vilnius County Waste Management Center for allowing them to carry out their research work at the Kariotiskes landfill.

\section{CONFLICT OF INTEREST}

The author declares that there is no conflict of interests regarding the publication of this paper. 


\section{REFERENCES}

Abichou, T., Kormi, T., Yuan, L., Johnson, T., Francisco, E., 2015. Modeling the effects of vegetation on methane oxidation and emissions through soil landfill final covers across different climates. Journal of Waste Manage 36, 230-240. https://doi.org/10.1016/j. wasman.2014.11.002.

Abichou, T., Powelson, D., Chanton, J., Escoriaza, S., 2006. Characterization of methane flux and oxidation at a solid waste landfill. Journal of Environmental Engineering 132, 220-228. https://doi. org/10.1061/(ASCE)0733-9372(2006)132:2(220).

Allen, G., Hollingsworth, P., Kabbabe, K., Pitt, J.R., Mead, S.I., Robers, G., Bount, M., Shallcross, D.E., Percival, C.J., 2019. The development and trial of an unmanned aerial system for the measurement of methane flux from landfill and greenhouse gas emission hotspots. Journal of Waste Manage 87, 883-892. https://doi.org/10.1016/j. wasman.2017.12.024.

Arif, M.A.S., Verstraete, W., 1995. Methane dosage to soil and its effect on plant growth. World J Microbiol Biotechnol 11(5), 529-35. https://doi.org/10.1007/BF00286368.

Battaglini, R., Raco, B., Scozzari, A., 2013. Effective monitoring of landfills: flux measurements and thermography enhance efficiency and reduce environmental impact. J. Geophys. Eng. 10, 64002. https://doi.org/10.1088/1742-2132/10/6/064002.

Bhandari, A.K., Kumar, A., 2012. Feature extraction using normalized difference vegetation index (NDVI): A Case Study of Jabalpur City. Proceedings of Communication, Computing \& Security. Proc. Technol. 6, 612- 621.

Bourn, M., Robinson, R., Innocenti, F., Scheutz, C., 2019. Regulating landfills using measured methane emissions: An English perspective. Journal of Waste Manage 87, 860-869, https://doi. org/10.1016/J.WASMAN.2018.06.032.

Capodici, M., Ciraolo, G., Trapani, D.D.I., Viviani, G., 2015. Remote sensing analysis coupled to field measurements for the evaluation of methane emissions from a landfill site: a case study. In: Proceedings Sardinia 2015, Fifteenth International Waste Management and Landfill Symposium.

Christensen, T. H., Cossu, R., Stegmann, R., 1996. Landfilling of Waste. Biogas, in: Christensen, T.H., Cossu, R., Stegmann, R. (Eds), New York, 860.

Cosyn, P., Miller, R., 2013. Trimble UX5 aerial imaging solution. A new standard in accuracy, robustness and performance for photogrammetric aerial mapping, in: Trimble Navigation Limited, Westminster, USA.

Daugela, I., Suziedelyte Visockiene, J., Aksamitauskas, Č.V., 2018. RPAS and GIS for landfill analysis. Tenth Conference on Interdisciplinary Problems in Environmental Protection and Engineering EKO-DOK 2018, Centrum Zdrowia i Wypoczynku Nowy Zdrój, Polanica-Zdrój, 16-18 April 2018.

De la Cruz, F.B., Green, R.B., Hater, G.R., Chanton, J.P., Thoma, E.D., Harvey, T.A., Barlaz, M.A., 2016. Comparison of field measurements to methane emissions models at a new landfill. Environ. Sci. Technol. 50, 9432-9441. https://doi.org/10.1021/acs.est.6b00415.

Desideri, U., Leonardi, D., Proietti, S., 2007. Application of infrared thermography to study behaviour of biogas captation wells. In: Proceedings Sardinia 2007, Eleventh International Waste Management and Landfill Symposium.

Environmental Protection Agency, 2000. Landfill manuals. Landfill site design. Wexford, Ireland. https://www.epa.ie/pubs/advice/waste/ waste/EPA_landfill_site_design_guide.pdf (accessed 25 February 2019).

El-Fadel, M., Khoury, R., 2000. Modeling settlement in MSW landfills: a critical review. Crit Rev Environ Sci Technol. 30, 327-361.

Feng, S, Leung, A.K., Ng, C.W.W., Liu, H.W., 2017. Theoretical analysis of coupled effects of microbe and root architecture on methane oxidation in vegetated landfill covers. Sci Total Environ. 599-600, 1954-1964

Fjelsted, L., Christensen, A.G., Larsen, J. E. Kjeldsen, P., Scheutz, C., 2019. Assessment of a landfill methane emission screening method using an unmanned aerial vehicle mounted thermal infrared camera - A field study. Journal of Waste Manage 87, 893-904. https://doi.org/10.1016/J.WASMAN.2018.05.031.

Fredenslund, A. M., Mønster, J., Kjeldsen, P., Scheutz, Ch., 2019. Development and implementation of a screening method to categorize the greenhouse gas mitigation potential of 91 landfills. Journal of Waste Manage 87, 915-923. https://doi.org/10.1016/j. wasman.2018.03.0050956-053X/.
Förstner, W., Wrobel, B.P., 2016. Photogrammetric Computer Vision. Statistics, Geometry, Orientation and Reconstruction. EBook, ISBN 978-3-319-11550-4.

Gandhi, G.M., Parthiban, S., Thummalu, N., Cristy, A., 2015. NDVI: vegetation change detection using remote sensing and GIS - A Case Study of Vellore Distric. Procedia Comput. Sci. 57, 1199-1210.

Gebert, J., Groengroeft, A., 2006. Passive landfill gas emission - influence of atmospheric pressure and implications for the operation of methane-oxidising biofilters. Waste Manage 26, 245-251. https://doi.org/10.1016/J.WASMAN.2005.01.022.

Gendebien, A., Pauwels, M., Constant, M., Ledrut-Damanet, M.J., Nyns, E.J., Fabry, R., Ferrero, G.L., Willumsen, H.C., Butson, J., 1992 Landfill gas from environment to energy (EUR-14017/1). Commission of the European Communities (CEC).

Hildmann, H. Kovacs, E, 2019. Review: Using Unmanned Aerial Vehicles (UAVs) as Mobile Sensing Platforms (MSPs) for Disaster Response, Civil Security and Public Safe. Drones 3, 59. https://doi. org/10.3390/drones3030059.

Innocenti, F., Robinson, R., Gardiner, T., Finlayson, A., Connor, A., 2017. Differential absorption lidar (DIAL) measurements of landfill methane emissions. Remote Sens. 9, 953.

Ishigaki, T., Yamada, M., Nagamori, M., Ono, Y., Inoue, Y., 2005. Estimation of methane emission from whole waste landfill site using correlation between flux and ground temperatures. Environ. Geol. 48, 845-853. https://doi.org/10.3390/RS9090953.

Kamieniak, J., Randviir, E.P., Banks, C.E., 2015. The latest developments in the analytical sensing of methane. Trends Analyt Chem. 73, $146-157$.

Kastek, M., Sosnowski, T., Orżanowski, T., Kopczyński, K., Kwaśny, M., 2009. Multispectral gas detection method. WIT Trans. Ecol. Envir. 123, 227-236. https://doi.org/10.2495/AIR09021.

Lando, A.T., Nakayama, H., Shimaoka, T., 2017. Application of portable gas detector in point and scanning method to estimate spatial distribution of methane emission in landfill. Waste Manage. 59, 255-266. https://doi.org/10.1016/J.WASMAN.2016.10.033.

Mahmood, K., Batool, S. A., Chaudhry, M. N. 2016. Studying bio-thermal effects at and around MSW dumps using Satellite Remote Sensing and GIS. Waste Manage. 55, 118-128.

Manzo, C., Mei, A., Zampetti, E., Bassani, C., Paciucci, L., Manetti, P. 2017. Top-down approach from satellite to terrestrial rover application for environmental monitoring of landfills. J. Sci. Total Environ. 584-585, 1333-1348. https://doi.org/10.1016/J.SCITOTENV.2017.01.033

Maurice, C., Bergman, A., Ecke, H., Lagerkvist, A., 1995. Vegetation as a biological indicator for landfill gas emissions: initial investigations. In: Proceedings: Sardinia 1995, Fifth International Landfill Symposium.

Mønster, J., Kjeldsen, P., Scheutz, C., 2019. Methodologies for measuring fugitive methane emissions from landfills - a review. Waste Manage, https://doi.org/10.1016/J.WASMAN.2018.12.047.

Ndanga, T.M., Bradley, R.L., Cabral, A.R., 2015. Does vegetation affect the methane oxidation efficiency of passive biosystems? Waste Manage, 38, 240-249.

NASA, 2018. Normalized Difference Vegetation Index (NDVI). Retrieved from The Earth Observatory: http://earthobservatory.nasa. gov/Features/MeasuringVegetation/measuring_vegetation_2.php (accessed 25 February 2019).

Remote Sensing Phenology, 2018. NDVI - the foundation. Retrieved from USGS: https://phenology.cr.usgs.gov/ndvi_foundation.php (accessed 25 February 2019).

Scheutz, C., Cassini, F., De Schoenmaeker, Jan, Kjeldsen, P., 2017. Mitigation of methane emissions in a pilot-scale biocover system at the AV Miljø Landfill, Denmark: 2. Methane oxidation. Waste Manage 63, 203-212.

Scheutz, C., Fredenslund, A.M., Nedenskov, J., Samuelsson, J., Kjeldsen P., 2011. Gas production, composition and emission at a modern disposal site receiving waste with a low organic content. Waste Manage 31, 946-955.

Scheutz, C., Bogner, J., Chanton, J.P., Blake, D., Morcet, M., Aran, C., Kjeldsen, P., 2008. Atmospheric emissions and attenuation of nonmethane organic compounds in cover soils at a French landfill. Waste Manage 28, 1892-1908

Scheutz, C., Bogner, J., Chanton, J., Blake, D., Morcet, M., Kjeldsen, P. 2003. Comparative oxidation and net emissions of methane and selected nonmethane organic compounds in landfill cover soils. Environ. Sci. Technol. 37, 5150-5158. 
Spokas, K., Bogner, J., 2011. Limits and dynamics of methane oxidation in landfill cover soils. Waste Manage. 31, 823-832. https:// doi.org/10.1016/j.wasman.2009.12.018.

Stern, J. C., Chanton, J., Abichou, T., Powelson, D., Yuan, L., Escoriza, S., Bogner, J., 2007. Use of a biologically active cover to reduce landfill methane emissions and enhance methane oxidation. Waste Manage 27, 248-1258.

Tanteri, L., Rossi, G., Tofani, V., Vannocci, P., Moretti, S. and Casagli, N., 2017. Multitemporal UAV survey for mass movement detection and monitoring. In: Workshop on World Landslide Forum. Springer, Cham.

Thenkabail, P.S., 2015. Remotely Sensed Data Characterization, Classification, and Accuracies. Remote Sensing Handbook. First ed. CRC Press. Boca Raton.

Thomasen, T.B., Scheutz, C., Kjeldsen, P., 2019. Treatment of landfill gas with low methane content by biocover systems. Waste Manage $84,29-37$.
USEPA, 2006. EPA Test Method (OTM 10), http://www.epa.gov/ttn/ emc/prelim/otm10.pdf (accessed June 2018)

Xu, L., Lin, X., Amen, J., Welding, K., McDermitt, D., 2014. Impact of changes in barometric pressure on landfill methane emission. Global Biogeochem. Cy. 28, 679-695. https://doi. org/10.1002/2013GB004571.

Xie, Y., Sha, Z., Yu, M., 2008. Remote sensing imagery in vegetation mapping: review. Plant Ecol. 1, 9-23.

Zhang, H., Hu, H., Yao, X., Zheng, K., Gan, Y., 2009. Estimation of above-ground biomass using $\mathrm{HJ}-1$ hyperspectral images in Hangzhou Bay, China. In: International Conference on Information, Engineering and Computer Science. https://doi.org/10.1109/ ICIECS.2009.5364800.

Yuan, H., Xiao, Ch., Zhan, W., Wang, Y., Shi, Ch., Ye, H., Jiang, K., ·ChunhuiZhou, Z., ·Wen, Y., Li, Q. 2019. Target Detection, Positioningand Tracking Using New UAV Gas Sensor Systems: Simulation and Analysis. Journal of Intelligent \& Robotic Systems 94, 871882. https://doi.org/10.1007/s10846-018-0909-2. 